\title{
Contamination of Fresh and Ensiled Maize by Multiple Penicillium Mycotoxins
}

\author{
M. A. Mansfield, A. D. Jones, and G. A. Kuldau
}

First and third authors: Department of Plant Pathology, The Pennsylvania State University, University Park 16802; and second author: Department of Biochemistry and Molecular Biology, Michigan State University, East Lansing 48824.

Accepted for publication 7 November 2007.

\begin{abstract}
Mansfield, M. A., Jones, A. D., and Kuldau, G. A. 2008. Contamination of fresh and ensiled maize by multiple Penicillium mycotoxins. Phytopathology 98:330-336.

Toxins produced by Penicillium species are reported in maize silage and have been associated with health problems in cattle. Our objectives were to evaluate the prevalence and dynamics of patulin (PAT), mycophenolic acid (MPA), cyclopiazonic acid (CPA), and roquefortine $\mathrm{C}$ (ROC) in fresh and ensiled maize. To achieve these objectives we developed a high-performance liquid chromatography method coupled with mass spectrometry to detect all four toxins simultaneously in silage. In addition we collected weather data, information on agronomic practices, and silage fermentation characteristics for each study site. Silage was

$0.12 \mu \mathrm{g} / \mathrm{g}$ (0.02 to 1.43$)$, and ROC $0.38 \mu \mathrm{g} / \mathrm{g}$ (0.01 to 5.71). ROC was the most frequently detected toxin $(60 \%)$, followed by MPA (42\%), CPA (37\%), and PAT (23\%). Of 120 samples tested, $15 \%$ contained no detectible levels of toxin, $25 \%$ were contaminated with one toxin, $32 \%$ with two, $18 \%$ with three, and $10 \%$ with all four toxins. All four mycotoxins were found in freshly harvested material, contradicting the belief that Penicillium toxin formation occurs exclusively during storage. We observed that weather conditions during specific growth stages of the crop affected the final concentration of toxins in freshly harvested maize. In ensiled material, PAT levels were affected by concentrations of propionic and isobutyric acids. Based on our data, Penicillium mycotoxins can form while the crop is in the field and after ensiling, suggesting that preventative measures should begin prior to ensiling.
\end{abstract} collected at harvest and after ensiling in 2001 and 2002 from 30 Pennsylvania dairies. The average concentration of toxins (range in parentheses) was: PAT $0.08 \mu \mathrm{g} / \mathrm{g}$ (0.01 to 1.21$)$, MPA $0.16 \mu \mathrm{g} / \mathrm{g}$ (0.02 to 1.30$)$, CPA
Additional keywords: corn silage, dairy cattle toxicosis.
Within the last several decades, knowledge of fungal contaminants in agricultural products has increased dramatically, particularly for toxins produced by plant pathogens such as Fusarium species. Occasionally, mycotoxins produced by saprophytic or opportunistic fungi, such as Penicillium species, are also present in agricultural commodities (55). Several mycotoxins produced by Penicillium spp., including cyclopiazonic acid (CPA) (63), patulin (PAT) (10,37), mycophenolic acid (MPA) (52), and roquefortine $\mathrm{C}$ (ROC) (3) are known to occur in maize based feeds including silage. In addition, there are reports of serious health problems occurring when cattle are exposed to these toxins. The majority of toxin production is thought to take place during storage, as some mycotoxigenic Penicillium will grow in conditions similar to silage with low water activity, low $\mathrm{pH}$, and oxygen concentration $(6,15,26)$. For example, $P$. roqueforti and the closely related $P$. paneum are often present in silage and they and their toxins have been isolated from material that is not visibly molded $(3,6)$.

Many toxigenic species of Penicillium are saprophytic on plant material and soil debris and Penicillium ear rot on maize can occur on ears damaged by birds and insects $(8,23)$. Several studies have found that Penicillium are among the most commonly isolated filamentous fungi $(1,11,14,22,24,44)$. The most frequently isolated Penicillium in silage is generally $P$. roqueforti $(3,43,58,61)$, which has recently been divided into three species, $P$. roqueforti, $P$. paneum, and $P$. carneum, based on analysis of rDNA genes and chemotaxonomic profiles (6). Of the $P$. roque-

Corresponding author: G. A. Kuldau; E-mail address: kuldau@psu.edu

doi:10.1094/PHYTO-98-3-0330

(C) 2008 The American Phytopathological Society forti group, only $P$. roqueforti and $P$. paneum have been reported in silage $(6,58)$. Both species produce ROC and $P$. roqueforti also produces PR-toxin and MPA, while $P$. paneum produces PAT $(6,40,41)$. Other species reported in silage include $P$. expansum, which will tolerate low $\mathrm{pH}$ and oxygen and produce $\mathrm{ROC}$ and PAT, $P$. crustosum and $P$. commune, which both produce CPA acid and ROC (13).

Both PAT and ROC have been implicated in cattle toxicoses, although clinical data on the affects of these toxins on cattle are not available, which is also true for MPA and CPA. ROC has been reported as a suspected causal agent in several cases of paralysis, abortion, and placental retention in cattle $(3,16,43,57)$. However, as the strains of $P$. roqueforti isolated in these cases may have been producing other mycotoxins as well, including PR-toxin, it is difficult to determine if ROC was the sole toxin responsible for the observed symptoms. In a somewhat conflicting study, Tuller et al. (60) found that ROC is not acutely toxic to sheep at levels generally encountered in silages. In several cases of suspected ROC toxicosis in dogs, animals that ingested food colonized by $P$. roqueforti suffered paralysis, tremors, and convulsions $(7,39,62)$, suggesting a neurotoxic effect. However, in several of these cases another toxin, penitrem A, was also present. Caution should also be used in interpreting the affects of these toxins as there may be significant differences in toxin sensitivity from dogs to ruminants and other species.

PAT has also been implicated in cattle health disorders, where several beef herds experienced tremors, paralysis, and death (51). In this particular case the PAT-producer was not a Penicillium sp., but rather Aspergillus clavatus. Autopsy of the affected animals revealed serious damage to the nervous system and PAT was detected from fungal cultures and in the feed. In another case, cattle that consumed $P$. roqueforti-infested silage experienced a 
loss of appetite, gastrointestinal hemorrhaging, and abortion (61). In this incident the suspected agents were PR-toxin and PAT, although no tests were performed on the feed to verify this hypothesis. PAT has also negatively impacts the metabolism of rumen microorganisms, suggesting that PAT exposure may result in a subtle decrease in overall animal health $(12,59)$.

Unlike PAT and ROC, MPA does not appear to be acutely toxic although it is a potent immunosuppressive agent and is used in anti-rejection therapy for organ transplant patients (4). In a study conducted with maize silage, MPA was reported in 38 of 135 samples and in some samples, the authors stated that the concentration of MPA was equivalent to $10 \%$ of the dose given to patients undergoing immunosuppressive therapy (52). In a recent study with sheep, Mohr et al. (2007) found that animals fed varying concentrations of MPA for 44 days suffered no significant effects from exposure (36). Although exposure to MPA may not result in an obvious decline in health, the immunosuppressive action of this toxin has been suggested to render animals more susceptible to infectious diseases and more sensitive to the presence of other mycotoxins (47).

In contrast to the toxins discussed above, there is no anecdotal or clinical information regarding the affects of CPA on cattle or other ruminants. In poultry, CPA exposure resulted in tremorgenic activity and lesions on the liver, kidney, and gastrointestinal tract (9). In addition to the direct health hazard that CPA may present, this toxin can also be excreted in milk and remains stable following pasteurization, and for extended periods of storage (46).

In general, our knowledge of the potential dangers presented by Penicillium mycotoxins in feed is fairly limited, as much of the information regarding the sensitivity of cattle to these toxins is anecdotal. Although some studies suggest that exposure to toxins such as ROC and MPA present a minor threat to ruminants, there is virtually no information regarding synergistic or additive effects when more than one toxin is present. Also, the few clinical studies performed on animal subjects have been strictly limited to the affects of acute, rather than chronic, toxin exposure. However, as there have been a limited number of studies addressing the natural prevalence of these toxins in silage, or factors affect their presence in silage, it is unclear whether costly animal studies are warranted. With these concerns in mind, our objective was to better understand the frequency, levels, and factors that affect contamination of silage by CPA, MPA, PAT, and ROC. These four toxins were selected to represent Penicillum species isolated in a previous work, including $P$. roqueforti, $P$. paneum, $P$. commune, $P$. crustosum, and $P$. expansum (30).

To achieve our objective, we developed an analytical method that coupled high-performance liquid chromatography (HPLC) with mass spectrometry, to detect and quantify these four toxins from fresh and ensiled maize collected over a 2-year period from Pennsylvania dairies. Using toxin data, information regarding the farms' agronomic practices, and site-specific weather data, our goal was to better understand the overall prevalence of Penicillium mycotoxins and identify factors that affect mycotoxin contamination of silage.

\section{MATERIALS AND METHODS}

Sample collection and preparation. Maize silage was collected from four geographically diverse regions in Pennsylvania (northeast $[\mathrm{NE}]$, northwest [NW], southeast [SE], and south central [SC]) at dairies with a history of cattle health problems within the previous 5 years (Fig. 1). Samples were collected at harvest and 3 to 6 months after ensiling, to determine if toxin levels changed during storage $(28,29)$. Harvest samples consisted of freshly chopped maize that was collected from a mechanical harvester as it made several passes within a field. Ensiled samples were removed either from several locations at the face of a structure (bunker or trench silo), or removed as the silage was emptied from the silo during feed out (upright silo). The sampling frequency of ensiled material was determined by the amount of silage fed per day at each farm. Samples were collected either every other day for 14 days for sites feeding 1 to 2 tons per day and every day for 7 days for sites feeding 3 to 4 (or more) tons per day. After initial sample collection, both harvest and ensiled samples were mixed by hand and subsampled to obtain a representative sample of 1 to $3 \mathrm{~kg}$. All samples were stored at $-80^{\circ} \mathrm{C}$ until toxin analysis. Prior to extraction, silage was dried at $55^{\circ} \mathrm{C}$ for 5 to 7 days, milled to a flour-like consistency in a ThomasWiley Mill (Thomas Scientific, Inc., Swedesboro, NJ), and $500 \mathrm{~g}$ was removed for analysis.

Toxin extraction and cleanup. The method used to extract CPA, MPA, PAT, and ROC was modified from that of Rundberget and Wilkins (50). All solvents used for extraction were of HPLC grade. For each sample, $10 \mathrm{~g}$ of silage was extracted for $1 \mathrm{~h}$ with $60 \mathrm{ml}$ of acetonitrile-water (9:1, vol/vol) (Burdick \& Jackson, Muskegon, MI; Milli-Q UV Plus System, Millipore, Billerica, MA) with $0.1 \%$ formic acid (EM Science, Gibbstown, NJ) on an automatic shaker at $300 \mathrm{rpm}$. Samples were centrifuged at $6,000 \times g$ for $10 \mathrm{~min}$ and $10 \mathrm{ml}$ was decanted for cleanup. Samples were defatted twice with $10 \mathrm{ml}$ of hexane (EM Science, Gibbstown, NJ) and the lower aqueous phase was removed for analysis. Defatted samples were transferred to an 11-ml vial and de-solvated to dryness under a stream of nitrogen at $65^{\circ} \mathrm{C}$. The residue was redissolved in $1 \mathrm{ml}$ acetonitrile, filtered with a prewet nylon filter (Acrodisc GHP $0.2 \mu \mathrm{M}$ filter, Pall Life Science, West Chester, PA), de-solvated a second time, and resuspended in $500 \mu \mathrm{l}$ of acetonitrile. Samples were stored in 2-ml amber vials at $4{ }^{\circ} \mathrm{C}$ until HPLC-mass spectrometry analysis.

Standards. Standards for CPA, MPA, PAT, and ROC (all toxins from Sigma-Aldrich, St. Louis, MO) were prepared by dissolving toxins in HPLC-grade acetonitirile to a final concentration of $100 \mu \mathrm{g} / \mathrm{ml}$.

HPLC-MS analysis. Immediately preceding analysis, samples were de-solvated to dryness and resuspended in $350 \mu \mathrm{l}$ of methanol (Mallinckrodt-Baker, Phillipsburg, NJ) and $150 \mu \mathrm{l}$ of $0.1 \%$ acetic acid (EM Science, Gibbstown, NJ). The solvent delivery system consisted of a Shimadzu LC-20AD HPLC with a Shimadzu SIL-5000 autosampler (Shimadzu Scientific Instruments, Columbia, MD) coupled to a Waters LCT Premier mass spectrometer (Waters Corp., Milford, MA) for detection. Chromatographic separation was achieved using a reverse phase Thermo Betasil C-18 column $(150 \times 2.1 \mathrm{~mm} ; 5 \mu \mathrm{M}$ particle size, pore size $60 \AA$ ) (Thermo, Bellefonte, PA). Solvents consisted of the following: $\mathrm{A}$, water amended with $0.05 \mathrm{M}$ ammonium acetate and $\mathrm{B}$, methanol with $0.05 \mathrm{M}$ ammonium acetate. The method began with $\mathrm{A}$ at $100 \%$ with a linear gradient program moving to $100 \% \mathrm{~B}$ from time 0 to $7.5 \mathrm{~min}$, holding at $\mathrm{B}$ from 7.5 to $12.5 \mathrm{~min}$, and

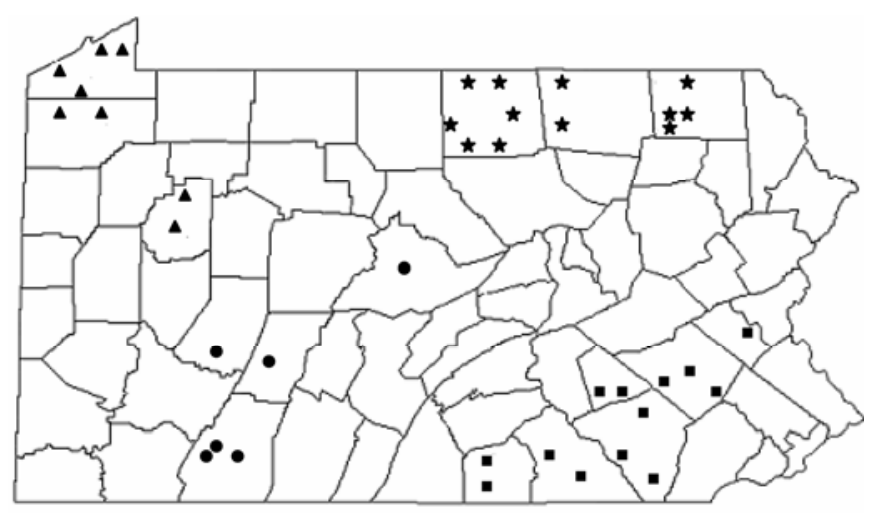

Fig. 1. Map of the relative locations of dairies where silage samples were collected. Symbols represent the four major dairy production regions Northeast, $\star$; Northwest, $\mathbf{\Delta}$; Southeast, $\mathbf{\square}$; and South central, $\bullet$. 
then re-equilibrating with $\mathrm{A}$ from 12.5 to $17.5 \mathrm{~min}$ before the next injection. The flow rate was constant at $0.3 \mathrm{ml}$ solvent per minute. The toxins were detected with an atmospheric pressure chemical ionization probe in the positive mode (APCI+). The instrument was set for selective ion detection for masses between 100 to $450 \mathrm{~m} / z$ where the masses of the toxins (the parent compound plus $\mathrm{H}^{+}$) were as follows: PAT $-\mathrm{m} / z 155, \mathrm{MPA}-\mathrm{m} / z 321, \mathrm{CPA}-\mathrm{m} / z$ 337, and ROC $-\mathrm{m} / z 390$ (Fig. 2). Data analyses were performed using Mass Lynx version 3.5 mass spectrometry software (Milford, MA) where toxin quantification was determined by comparing sample peaks to an external mixed standard of each of the four toxins.

Evaluation of extraction and detection method. When test silage samples $(N=12)$ were spiked with each of the four toxins (range of 0.5 to $5 \mu \mathrm{g}$ of toxin per g of silage), extracted, separated, and detected with the methods described above, the percent recoveries were as follows: PAT $=82$ to $89 \%, \mathrm{MPA}=86$ to $94 \%$, $\mathrm{CPA}=80$ to $87 \%$, and $\mathrm{ROC}=88$ to $92 \%$ with a limit of detection of $10 \mathrm{ng} / \mathrm{g}$ for each toxin.

Evaluation of sample characteristics. From each participating dairy, information was collected on how the crop was managed. Characteristics included crop rotation with a broadleaf crop (yes or no), the tillage system used (moldboard, no-till, variety of systems used), whether an inoculant or acid additive was added prior to ensiling (yes or no), and what type of silo the material was stored in (upright, bunker/trench, or bag silo). Ensiled material was also evaluated by Cumberland Valley Analytical Services

A

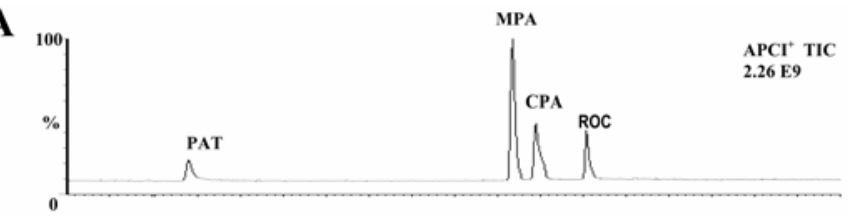

B

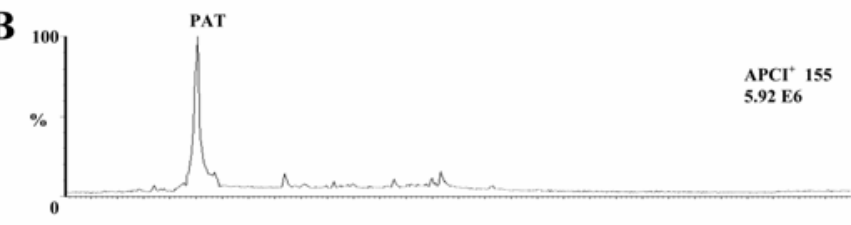

C

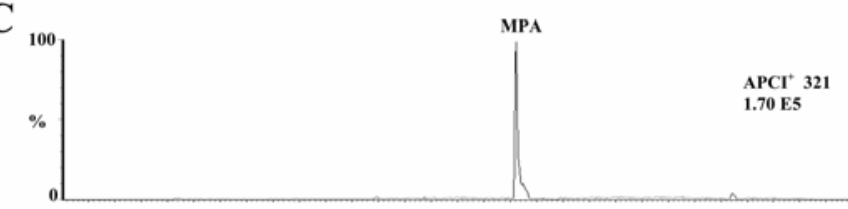

D

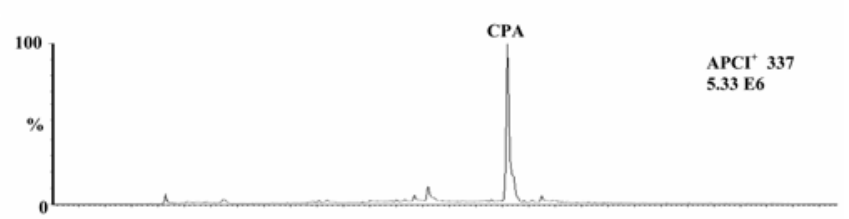

$\mathbf{E}$

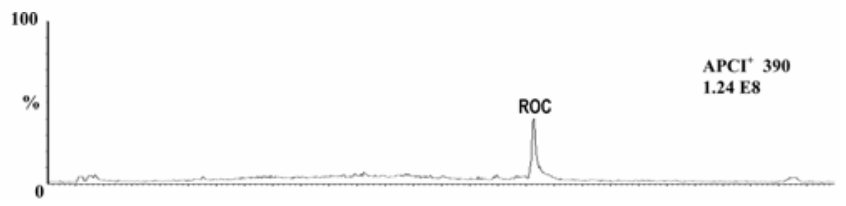

Fig. 2. Liquid chromatography-mass spectrometry chromatograms showing $\mathbf{A}$, total ion chromatogram for a mixed standard of four mycotoxins and reconstructed ion chromatograms showing silage samples contaminated with $\mathbf{B}$, patulin (PAT) $\mathrm{m} / z$ 155, C, mycophenolic acid (MPA) $\mathrm{m} / z, 321$, D, cyclopiazonic acid (CPA) $\mathrm{m} / z$ 337, and $\mathbf{E}$, roquefortine $C$ (ROC) $\mathrm{m} / z$ 390. Mass is at the upper right of each chromatogram and corresponds to the gain of $\mathrm{H}^{+}$ compared with the parent compound, the total ion count (TIC) is given for the standard. The number at the lower right is absolute signal intensity corresponding to the $100 \%$ level indicated on the axis.
(Hagerstown, MD) for percent dry matter, $\mathrm{pH}, \mathrm{NH}_{4}$ content, and the concentration of volatile fatty acids (lactic, acetic, propionic, butyric, and isobutyric) (53).

Site-specific weather data collection. For each of the study sites, estimated daily weather data for the minimum, maximum, and average temperature, total precipitation, average relative humidity, wetness hours, growing degree day (base $10^{\circ} \mathrm{C}$ ), precipitation minus evaporation (day 1 planting date), and a hybrid growth prediction (based on planting date) from tasselling (VT) through maturity (R6), were provided by ZedX Inc. (Bellefonte, PA) $(2,27,48)$. Prior to statistical analysis, daily weather variables were averaged to a single value for each growth stage.

Statistical analyses. All statistical analyses were performed using a 95\% confidence interval (64). Toxin occurrence in silage from both seasons (2001 and 2002) and from harvest and ensiled samples were compared using the Mann-Whitney test (Minitab version 13.32, Minitab Inc., State College, PA). Differences between toxin levels in these samples were evaluated with the Student's paired $t$ test. The occurrence of toxins between the four regions was evaluated with the Kruskal-Wallis test, while differences in levels were evaluated with a general linear model. To determine if agronomic practices, silage fermentation characteristics, or weather variables during each crop growth stage had a relationship to toxin concentration in silage, we used Pearson's correlation. Kendall's correlation (PROC CORR procedure in SAS software, SAS Institute Inc., Cary, NC) was used to understand the relationship between these variables and toxin occurrence in silage.

\section{RESULTS}

Levels and occurrence of PAT, CPA, MPA, and ROC in fresh and ensiled maize. The average concentration of toxins (with the range in parentheses) in maize silage from both seasons $(N=120)$ was: PAT $0.08 \mu \mathrm{g} / \mathrm{g}(0.01$ to 1.21$)$, MPA $0.16 \mu \mathrm{g} / \mathrm{g}(0.02$ to 1.30$)$, CPA $0.12 \mu \mathrm{g} / \mathrm{g}$ (0.02 to 1.43$)$, and ROC $0.38 \mu \mathrm{g} / \mathrm{g}(0.01$ to 5.71). The frequency of toxin contamination in the same samples was: ROC 60\%, MPA 42\%, CPA 37\%, and PAT 23\%. Of 120 samples, $15 \%$ had no detectible amount of toxin, $25 \%$ were contaminated with a single toxin, $32 \%$ with two, $18 \%$ with three, and $10 \%$ with all four toxins. In terms of toxin co-occurrence, ROC was the most frequent co-contaminant, occurring in $83 \%$ of samples with more than one toxin present. ROC occurrence was positively correlated to the presence of MPA (Kendall's correlation) where $77 \%$ of the samples positive for MPA also contained ROC.

All four mycotoxins were detected in freshly harvested maize silage samples: $17 \%$ contained PAT, $27 \%$ MPA, 30\% CPA, and $50 \% \operatorname{ROC}(N=60)$. The average (range in parentheses) amounts of toxin in fresh samples were as follows: PAT $0.05 \mu \mathrm{g} / \mathrm{g}(0.01$ to $0.91)$, MPA $0.06 \mu \mathrm{g} / \mathrm{g}$ (0.08 to 0.60$)$, CPA $0.05 \mu \mathrm{g} / \mathrm{g}$ (0.02 to 0.38 ), and ROC $0.20 \mu \mathrm{g} / \mathrm{g}$ (0.02 to 1.10$)$.

There were no differences detected between the 2001 and 2002 growing seasons in terms of average toxin concentration or occurrence and as such, data for both seasons was considered a single dataset. All four toxins were present in both harvest and ensiled samples and MPA, CPA, and ROC were present at significantly higher average levels in ensiled material (Fig. 3A). Although there were no significant differences between levels of PAT in harvest and ensiled maize, this toxin was found more often in ensiled samples $(60 \%)$ than in those that were freshly harvested $(8 \%)$ (Fig. 3B).

Between the four study regions (Fig. 1) there were differences in the levels of CPA and ROC (Fig. 4A). In general, it appears that the southern regions had higher concentrations of these toxins, with SE having an average of $0.15 \mu \mathrm{g} / \mathrm{g}$ CPA and $0.50 \mu \mathrm{g} / \mathrm{g}$ ROC and SC with $0.26 \mu \mathrm{g} / \mathrm{g} \mathrm{CPA}$ and $0.46 \mu \mathrm{g} / \mathrm{g}$ of ROC. For MPA and $\mathrm{PAT}$, there were no significant differences observed among the four regions (Figs. 4A and B). 
Relationship between toxin contamination in maize silage, agronomic practices, fermentation characters, and seasonal weather conditions. There was no relationship between toxin levels and occurrence in maize silage and agronomic practices. However, there was a positive correlation between PAT levels in ensiled maize and propionic $(R=0.287, P \leq 0.026)$ and isobutyric acid $(R=0.252, P \leq 0.046)$. Therefore, it appears that higher PAT levels occurred in samples with higher concentrations of these acids.

Patterns of toxin concentration with some of the seasonal weather variables as summarized in Table 1 . In general, toxin concentration appeared to be most strongly impacted by temperature and precipitation variables during tasselling (VT) and early kernel development (R1 to R3; silking through milk stages). Levels of MPA toxin were higher in samples where the average minimum temperature and relative humidity were higher during $\mathrm{R} 2$ or blister stage. Levels of CPA were lower in samples where the maximum temperature, average temperature, and precipitation minus evaporation values were higher than average during tasselling. However, toxin levels were higher in samples where precipitation was higher than average during silking (R1) and the precipitation minus evaporation, relative humidity, and wetness hours were higher during the blister stage (R2). Levels of PAT were higher in samples where there were more wetness hours than average during silking (R1) and in samples where the precipitation and precipitation minus evaporation values were higher than average. ROC levels appeared to be affected later in plant development than MPA, CPA, or PAT. ROC concentrations were higher in samples at blister (R2) when temperatures were higher
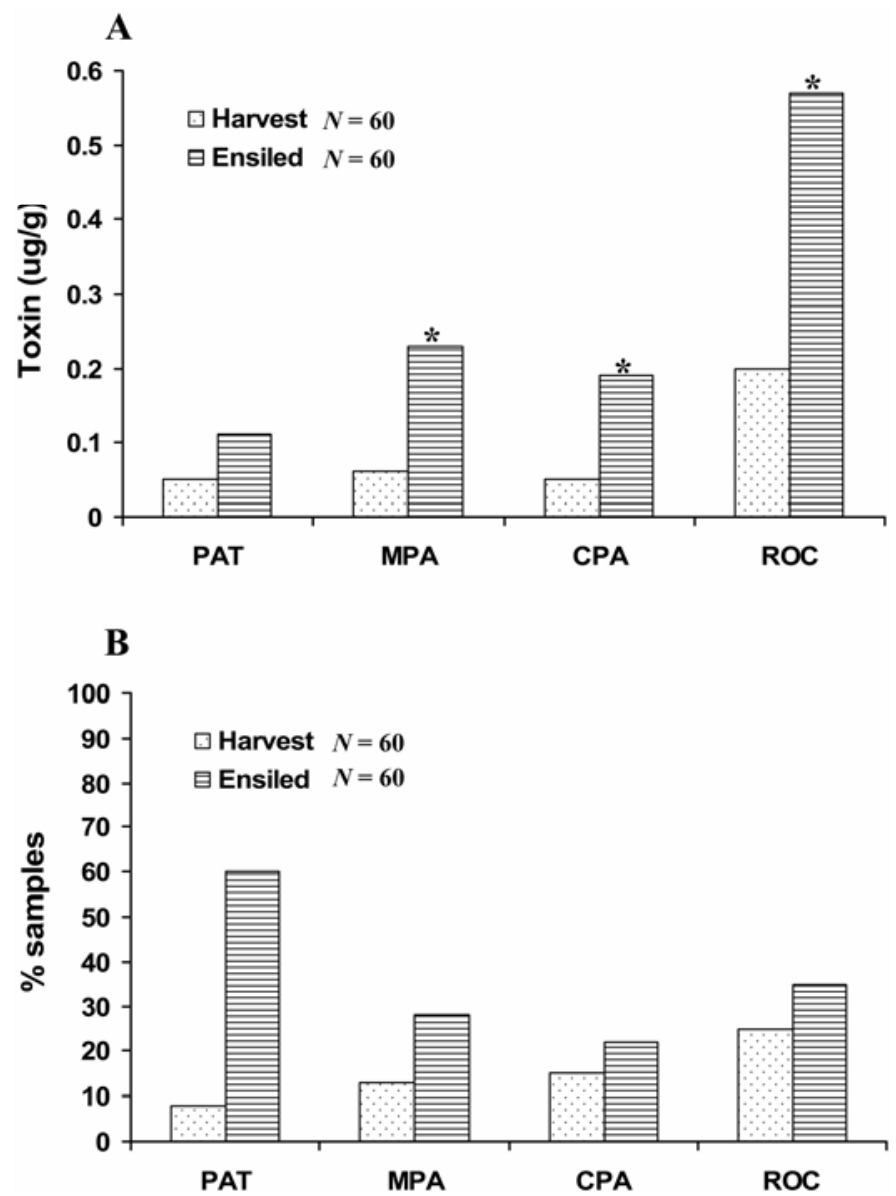

Fig. 3. A, Average concentration of Penicillium mycotoxins in maize silage. Asterisks over bars indicate samples (harvest or ensiled) with significantly $(P \leq 0.05)$ higher toxin concentration. B, Frequency of Penicillium mycotoxins in fresh and ensiled maize samples. Patulin (PAT), mycophenolic acid (MPA), cyclopiazonic acid (CPA), and roquefortine C (ROC). than average and the relative humidity lower than average. Levels were also higher in samples where at the milk and dough stage (R3 and R4) temperatures were higher than average and in samples where at physiological maturity there was less moisture than average present.

\section{DISCUSSION}

The natural occurrence of Penicillium toxins in maize silage has been addressed by several other researchers, primarily located in Europe. As far as we are aware, this is the first study to comprehensively address contamination by several Penicillium toxins in fresh and ensiled North American maize silage. In 2000, Schneweis et al. (52) found that $32 \%$ of the silage samples in Germany contained MPA at a range of 0.2 to $350 \mu \mathrm{g} / \mathrm{g}$ with an average of $14 \mu \mathrm{g} / \mathrm{g}$ of toxin. MPA was slightly more prevalent in our samples $(42 \%)$ but the average amount of toxin was comparable, however, it was detected at a lower range. One explanation for their observations is that they purposely selected samples that were highly infested with Penicillium species, whereas we randomly selected our samples and observed no visible contamination.

In a laboratory silo, Muller and Amend (37) observed that MPA and PAT were produced in silage at concentrations of 3.56 and $3.06 \mu \mathrm{g} / \mathrm{g}$, respectively. In this case, silage was deliberately inoculated with a strain of $P$. roqueforti known to produce these toxins in culture. Interestingly, they observed that production of MPA and PAT in silage was preceded by an increase of $\mathrm{pH}$, which is somewhat in contrast to our observations where PAT contamina-
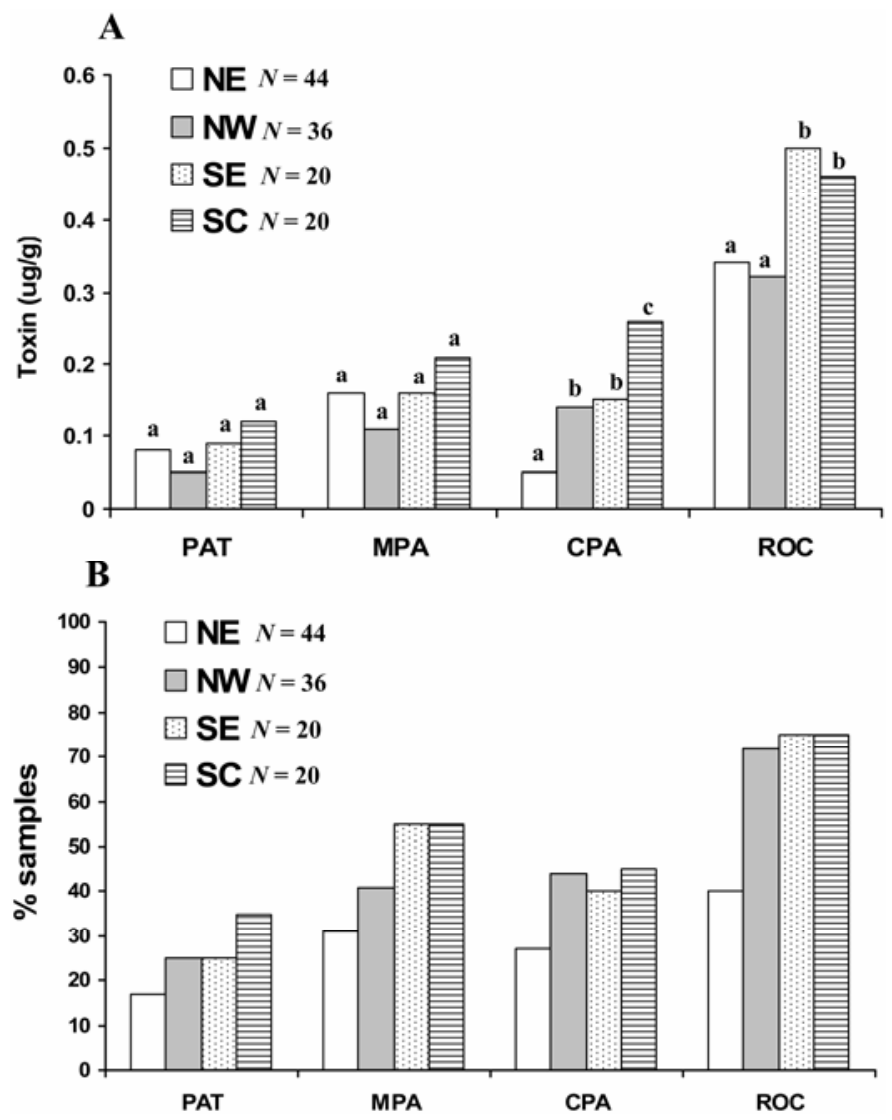

Fig. 4. A, average concentration of Penicillium mycotoxins in maize silage from the four different geographical sampling regions. NE - northeast, NW - northwest, SE - southeast, and SC - south central. Bars of the same toxin followed by a different letter are significantly different at $P \leq 0.05$. B, Frequency of Penicillium mycotoxins in maize silage samples from the four different geographical sampling regions. Patulin (PAT), mycophenolic acid (MPA), cyclopiazonic acid (CPA), and roquefortine $\mathrm{C}$ (ROC). 
tion was positively correlated to levels of propionic and isobutyric acids. Propionic acid is naturally present in silage and has a strong inhibitory affect on fungal growth and toxin production $(17,38,56)$ and therefore, it is unclear why its presence would positively affect that of PAT. Higher levels of isobutyric acid are associated with fungal spoilage in silage, so it is somewhat unsurprising that its presence is correlated with PAT levels. However, the levels of both of these acids in our silage samples were well within acceptable ranges delineated for quality silage (49). As far as we are aware, this is the first report of maize silage naturally contaminated with PAT as previous studies have focused on PAT production by isolates recovered from silage $(12,51)$ or from a laboratory silo (37).

Yu et al. (63) observed CPA in $87 \%$ of samples of mixed feed and silage with an average of $0.34 \mu \mathrm{g} / \mathrm{g}$ of toxin at a range of 0.12 to $1.82 \mu \mathrm{g} / \mathrm{g}$. The average levels and range of CPA in this study is comparable to what we observed, although we found CPA contamination at lower frequency in ensiled samples $(40 \%)$.

ROC was the most frequently occurring toxin in our samples and the most common co-contaminant with other toxins, particularly MPA. This was expected as $P$. roqueforti produces both of these toxins and in an earlier work (30) we isolated $P$. roqueforti, $P$. paneum, $P$. commune, $P$. crustosum, and $P$. expansum from a subset of freshly harvested and ensiled maize samples included in this study. By far P. roqueforti was the most prevalent Penicillium species, which likely explains the prevalence of ROC and MPA in the silage samples. Auerbach et al. (3) detected ROC in 54\% of the silage samples assessed at an average of $8.5 \mu \mathrm{g} / \mathrm{g}$ and a range of 0.2 to $36.0 \mu \mathrm{g} / \mathrm{g}$. The concentrations of ROC in this study are significantly higher than what we found, however, these authors also selected some samples that were visibly infested with Penicillium species.

One of the most significant findings of this work may be that Penicillium toxins were present in the freshly harvested maize samples as well as those that were ensiled. In general, the levels and frequencies of the four toxins in fresh material were lower than that of ensiled samples (Fig. 3) however, many of the fresh samples were also co-contaminated with Penicillium toxins. The presence of these toxins in fresh samples is not completely surprising as several toxigenic Penicillium species were isolated and detected in freshly harvested material (30). In that same study, the majority of Penicillium isolated from fresh maize survived the ensiling process and were isolated from the corresponding ensiled sample, which is likely why all four toxins were present in ensiled samples. The presence of mycotoxigenic Penicillium species on freshly harvested maize grain and plant material has been well documented $(19,23,26,34)$. There have also been a significant number of studies where toxin production by Penicillium species in vitro is dependent on water activity, temperature, relative humidity, and other factors $(15,19,20,26,31,32,34,45,54)$. Therefore, it is not surprising that we observed that temperature and water availability during the growing season affected the presence of the four toxins. Similar to in vitro studies, toxin production was positively affected by higher temperatures and water availability $(26,31,35,45,54,56,58)$ except in the case of ROC where higher toxin levels were present in samples with lower moisture availability during physiological maturity. As this is the first study to look at seasonal weather variables and how they affect the presence of Penicillium mycotoxins in maize, it is unclear as to why temperature and water availability, particularly during reproductive and early kernel development, had an effect on toxin levels. One possibility is that conditions that stress the plant (low water availability and higher than average temperatures) are also more favorable for colonization by fungi, such as Penicillium species. Fungal colonization is more likely on maize that is stressed or damaged (42), and Blaney et al. (5) observed a high incidence of fungi (including Penicillium spp.) and toxins in corn that was drought stressed early in the growing season. Both the 2001 and 2002 growing seasons (April to October) had higher than average temperatures and lower precipitation values where 2001 ranked 53rd (out of 108 recorded seasons) as warmest and 28th as driest, and 2002 sixth as warmest and 24th as driest (National Climatic Data Center, Ashville, NC). Therefore, our observations may be primarily related to conditions that stress the plant in addition to favoring fungal growth and toxin production.

Given that there has been little work addressing the overall toxicity of PAT, MPA, CPA, and ROC to cattle, it is unclear if the levels we observed in silage should be a health concern. Certainly the presence of multiple toxins in the same samples is concerning due to the additive or synergistic affects they may cause. Also of concern is the fact that formation of these toxins begins in the field and therefore, future management strategies should not exclusively focus on sanitation practices during ensiling and storage. It is hoped that the data presented here will motivate

TABLE 1. Relationships between weather variables and Penicillium mycotoxin concentrations in freshly harvested silage

\begin{tabular}{|c|c|c|c|c|c|c|}
\hline Toxin & Stage $^{a}$ & Variable $^{b}$ & Average $^{c}$ & Range $(N=60)$ & Corr. coeff. $^{\mathrm{d}}$ & $P$ value \\
\hline \multirow[t]{2}{*}{ MPA } & $\mathrm{R} 2$ & TMIN & 16.6 & 11.2 to 21.4 & 0.274 & 0.034 \\
\hline & & RHUM & 71.2 & 60.2 to 77.1 & 0.266 & 0.040 \\
\hline \multirow[t]{7}{*}{ CPA } & VT & TMAX & 28.8 & 24.8 to 32.8 & -0.253 & 0.051 \\
\hline & & ATEMP & 23.1 & 18.7 to 26.4 & -0.265 & 0.041 \\
\hline & & PVAP & -0.51 & -0.91 to 0.76 & -0.286 & 0.026 \\
\hline & $\mathrm{R} 1$ & PREC & 0.05 & 0 to 0.26 & 0.268 & 0.039 \\
\hline & $\mathrm{R} 2$ & PVAP & -0.46 & -0.15 to -0.76 & -0.270 & 0.028 \\
\hline & & RHUM & 71.2 & 60.2 to 77.1 & 0.290 & 0.024 \\
\hline & & WHR & 9.8 & 3.2 to 16.2 & 0.283 & 0.029 \\
\hline \multirow[t]{3}{*}{ PAT } & $\mathrm{R} 1$ & WHR & 8.4 & 0 to 17.5 & 0.293 & 0.023 \\
\hline & R3 & PREC & 0.08 & 0.02 to 0.17 & 0.304 & 0.018 \\
\hline & & PVAP & -63.0 & -82.0 to -46.2 & 0.292 & 0.023 \\
\hline \multirow[t]{8}{*}{$\mathrm{ROC}$} & $\mathrm{R} 2$ & TMAX & 27.6 & 23.1 to 31.8 & 0.357 & 0.005 \\
\hline & & ATEMP & 22.1 & 17.4 to 26.0 & 0.355 & 0.009 \\
\hline & & RHUM & 71.2 & 60.2 to 77.1 & -0.265 & 0.040 \\
\hline & R3 & TMAX & 25.7 & 19.0 to 32.9 & 0.269 & 0.038 \\
\hline & & ATEMP & 20.0 & 13.7 to 27.0 & 0.279 & 0.031 \\
\hline & $\mathrm{R} 4$ & ATEMP & 18.1 & 8.6 to 27.5 & 0.285 & 0.041 \\
\hline & R6 & PREC & 0.20 & 0.0 to 0.71 & -0.431 & 0.011 \\
\hline & & PVAP & -0.23 & -0.84 to 0.43 & -0.395 & 0.021 \\
\hline
\end{tabular}

a Growth stages are as follows: VT - tassel, R1 - silking, R2 - blister, R3 - milk, R4 - dough, R5 - dent, and R6 - maturity (47).

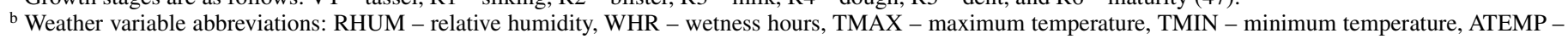
average temperature, PVAP - precipitation minus evaporation, and PREC - precipitation.

c Average for variables have the following units: RHUM as a percent, WHR as hours, temperature in degrees Celsius, and PREC as precipitation in centimeters.

d Pearson's correlation coefficient. 
others to determine the affects of cattle exposure to these toxins and potentially develop preventative strategies against toxin contamination. Although we saw no reduction in toxin frequency or levels during ensiling, there have been two reports of silage remediation from toxin contamination. Levy et al. (25) observed that toxigenic Penicillium isolates and PAT production was inhibited or reduced in the presence of various yeast isolates. Using oxidative degradation, McKenzie et al. (33) reduced in vitro amounts of CPA and PAT. Strategies such as these may be adapted in the future to combat mycotoxin contamination of silages and provide more high-quality feeds to improve animal health. Some of the observations we have made in this study, particularly those of weather variables and their affect on preharvest mycotoxin contamination, may provide direction for data collection and model development to predict when conditions are favorable for toxin formation. Such strategies have been quite successful in predicting favorable conditions for the formation of other mycotoxins (18) and may be applied to warning systems and better control strategies for Penicillium toxins.

\section{ACKNOWLEDGMENTS}

This research was funded by agricultural research funds administered by the Pennsylvania Department of Agriculture. We acknowledge participating dairy producers as well as Pennsylvania State University Extension Educators, and representatives of Agway Inc. (Richmond, VA), Pennfield Inc. (Lancaster, PA), and E. M. Brown and Sons Inc. (Douglasville, PA) who identified participants. We also thank B. Dombroski and D. Archibald for technical assistance and S. Witiak and S. Kang for reviewing the manuscript.

\section{LITERATURE CITED}

1. Aleksandrov, M. 1986. The mycoflora of corn silage. Vet. Med. Nauki. 23:57-60.

2. Allen, J. C. 1976. A modified sine wave method for calculating degree days. Environ. Entomol. 5:338-396.

3. Auerbach, H., Oldenburg, E., and Weissbach, F. 1998. Incidence of Penicillium roqueforti and roquefortine $\mathrm{C}$ in silages. J. Sci. Food Agr. 76:565-572.

4. Bentley, R. 2000. Mycophenolic acid: A one hundred year odyssey from antibiotic to immunosuppressant. Chem. Rev. 100:3801-3825.

5. Blaney, B. J., Ramsey, M. D., and Tyler, A. L. 1986. Mycotoxins and toxigenic fungi in insect-damaged maize harvested during 1983 in Far North Queensland. Aust. J. Agric. Res. 37:235-244.

6. Boysen, M. E., Jacobsson, K. G., and Schnurer, J. 2000. Molecular identification of species from the Penicillium roqueforti group associated with spoiled animal feed. Appl. Environ. Microbiol. 66:1523-1526.

7. Boysen, S. R., Rozanski, E. A., Chan, D. L., Grobe, T. L., Fallon, M. J., and Rush, J. E. 2002. Tremorgenic mycotoxicosis in four dogs from a single household. J. Am. Vet. Med. Assoc. 221:1420.

8. Carson, M. L. 1999. Diseases of minor importance and limited occurrence. Pages 23-25 in: Compendium of Corn Diseases. 3rd ed. D. G. White, ed. The American Phytopathological Society, St. Paul, MN.

9. Dorner, J. W., Cole, R. J., Lomax, L. G., Gosser, H. S., and Diener, U. L. 1983. Cyclopiazonic acid production by Aspergillus flavus and its effects on broiler chickens. Appl. Environ. Microbiol. 46:698-703.

10. Dutton, M. F., Westlake, K., and Anderson, M. S. 1984. The interaction between additives, yeast and patulin production in grass silage. Mycopathologia 87:29-33.

11. El-Shanawany, A. A., Mostafa, M. E., and Barakat, A. 2005. Fungal populations and mycotoxins in silage in Assiut and Sohag governorates in Egypt, with a special reference to characteristic Aspergilli toxins. Mycopathologia 159:281-289.

12. Escoula, L. 1992. Patulin production by Penicillium granulatum and inhibition of ruminal flora. J. Environ. Pathol. Toxi. 11:45-48.

13. Frisvad, J. C., and Filtenborg, O. 1989. Terverticillate penicillia: Chemotoxonomy and mycotoxin production. Mycologia 81:837-861.

14. Garon, D., Richard, E., Sage, L., Bouchard, V., Pottier, D., and Lebailly, P. 2006. Mycoflora and multimycotoxin detection in corn silage: Experimental study. J. Agric. Food Chem. 54:3479-3484.

15. Gock, M. A., Hocking, A. D., Pitt, J. I., and Poulos, P. G. 2003. Influence of temperature, water activity and $\mathrm{pH}$ on growth of some xerophilic fungi. Int. J. Food. Microbiol. 81:11-19.

16. Haggblom, P. 1990. Isolation of roquefortine C from feed grain. Appl.
Environ. Microbiol. 56:2924-2926.

17. Higgenbotham, G. E., Mueller, S. C., Bolsen, K. K., and DePeters, E. J. 1998. Effects of inoculants containing propionic acid bacteria on fermentation and aerobic stability of corn silage. J. Dairy Sci. 81:2185-2192.

18. Hooker, D. C., Schaafsma, A. W., and Tamburic-Illincic, L. 2002. Using weather variables pre and post heading to predict deoxynivalenol content in winter wheat. Plant Dis. 86:611-619.

19. Jimenez, M., Sanchis, V., Santamaria, P., and Hernandez, E. 1985. Penicillium in pre-harvest corn from Valencia (Spain). I. Influence of different factors on contamination. Mycopathologia 92:53-57.

20. Kokkonen, M., Jestoi, M., and Rizzo, A. 2005. The effect of substrate on mycotoxin production of selected Penicillium strains. Int. J. Food. Microbiol. 99:207-214.

21. Kozlovskii, A. G., Soloveva, T. F., Reshetilova, T. A., and Skryabin, G. K. 1981. Biosynthesis of roquefortine and 3, 12-dihydroroquefortine by the culture Penicillium farinosum. Experientia 37:472-473.

22. Krustev, E. A. K. 1898. Microflora in corn silage. Vet. Med. Nauki. 18:8891.

23. Kurtzman, C. P., and Ciegler, A. 1970. Mycotoxin from a blue-eye mold of corn. Appl. Microbiol. 20:204-207.

24. Le Bars, J., and Escoula, L. 1973. Toxigenic fungi of dry fodders and silage. Bull. Int. Epizooties. 79:1213-1246.

25. Levy, R. M., Hayashi, L., Carreiro, S. C., Pagnocca, F. C., and Hirooka, E. Y. 2002. Inibition of toxic isolates of Penicillium and biodegradation of patulin promoted by yeast isolates. Rev. Bras. Armazenamento. 27:41-47.

26. Magan, N., and Lacey, J. 1984. Effect of temperature and $\mathrm{pH}$ on water relations of field and storage fungi. Trans. Br. Mycol. Soc. 82:71-81.

27. Magarey, R. D., Seem, R. C., Russo, J. M., Zack, J. W., Waight, K. T., Travis, J. W., and Oudemans, P. V. 2001. Site-specific weather information without on-site sensors. Plant Dis. 85:1213-1226.

28. Mansfield, M. A., Archibald, D. D., Jones, A. D., and Kuldau, G. A. 2007. Relationship of spinganine analog mycotoxin contamination in maize silage to seasonal weather conditions and to agronomic and ensiling practices. Phytopathology 97:504-511.

29. Mansfield, M. A., DeWolf, E. D., and Kuldau, G. A. 2005. Relationships between weather conditions, agronomic practices and fermentation characters with deoxynivalenol content in fresh and ensiled maize. Plant Dis. 89:1151-1157.

30. Mansfield, M. A., and Kuldau, G. A. 2007. Microbiological and molecular determination of mycobiota in fresh and ensiled maize silage. Mycologia 99:269-278.

31. Marin, S., Sanchis, V., Saenz, R., Ramos, A. J., Vinas, I., and Magan, N. 1998. Ecological determinants and growth of some Aspergillus and Penicillium spp. from maize grain. J. Appl. Microbiol. 84:25-36.

32. McCallum, J. L., Tsao, R., and Zhou, T. 2002. Factors affecting patulin production by Penicillium expansum. J. Food Prot. 65:1937-1942.

33. McKenzie, K. S., Sarr, I. A. B., Mayura, K., Bailey, R. H., Miller, D. R., Rogers, T. D., Norred, W. P., Voss, K. A., Plattner, R. D., Kubena, L. F., and Phillips, T. D. 1997. Oxidative degradation and detoxification of mycotoxins using a novel source of ozone. Food Chem. Toxicol. 35:807820 .

34. Mislivec, P. B., and Tuite, J. F. 1970. Temperature and relative humidity requirements of species of Penicillium isolated from yellow dent corn. Mycologia 62:74-88.

35. Mislivec, P. B., Dieter, C. T., and Bruce, V. R. 1975. Effect of temperature and relative humidity on spore germination of mycotoxigenic species of Aspergillus and Penicillium. Mycologia 67:1187-1189.

36. Mohr, A. I., Lorentz, I., Baum, B., Hewicker-Trautwein, M., Pfaffl, M., Dzidic, A., Meyer, H. D., Bauer, J., and Meyer, K. 2007. Influence of oral application of mycophenolic acid on the clinical health status of sheep. J. Vet. Med. A. 54:76-81.

37. Muller, H. M., and Amend, R. 1997. Formation and disappearance of mycophenolic acid, patulin, penicillic acid, and PR toxin in maize silage inoculated with Penicillium roqueforti. Arch. Anim. Nutr. 50:213-225.

38. Muller, H. M., and Thaler, M. 1981. Propionic acid preservation of corn following inoculation with molds and yeasts. Arch. Tierernahr. 31:789799.

39. Naude, T. W., O’Brien, O. M., Rundberget, T., McGregor, A. D., Roux, C., and Flaoyen, A. 2002. Tremorgenic neuromycotoxicosis in 2 dogs ascribed to the ingestion of penitrem A and possibly roquefortine in rice contaminated with Penicillium crustosum. J. S. Afr. Vet Assoc. 73:211215.

40. Nielsen, K. F., Sumarah, M. W., Frisvad, J. C., and Miller, J. D. 2006. Production of metabolites from the Penicillium roqueforti complex. J. Agric. Food Chem. 54:3756-3763.

41. O'Brien, M., Nielsen, K., O'Kiely, P., Forristal, P. D., Fuller, H. T., and Frisvad, J. C. 2006. Mycotoxins and other secondary metabolites produced in vitro by Penicillium paneum Frisvad and Penicillium roqueforti Thom isolated from baled grass silage in Ireland. J. Agric. Food Chem. 54:9268-9276. 
42. Odvody, G. N., Spencer, N., and Remmers, J. 1997. A description of silk cut, a stress-related loss of kernel integrity in preharvest maize. Plant Dis. 71:439-444.

43. Ohmomo, S., and Kitamoto, H. 1994. Detection of roquefortines in Penicillium roqueforti isolated from moulded silage. J. Sci. Food Agric. 64:211-215.

44. Pelhate, J. 1977. Maize silage: Incidence of moulds during conservation. Folia Vet. Lat. 7:1-16.

45. Podgorska, E. 1992. Effect of Penicillium expansum culture conditions on patulin production. Acta Microbiol. Pol. 41:89-95.

46. Prasongsidh, B. C., Kailaspathy, K., Skurray, G. R., and Bryden, W. L. 1998. Kinetic study of cyclopiazonic acid during the heat processing of milk. Food Chem. 62:467-472.

47. Riley, R. T. 1998. Pages 227-253 in: Mechanistic Interactions of Mycotoxins: Theoretical Considerations. Marcel Dekker, Inc., New York.

48. Ritchie, S. W., and Benson, G. O. 1993. How a corn plant grows. Special report number 48. Iowa State University Science and Technology Cooperative Extension Service, Ames, IA.

49. Roth, G. W., and Heinrichs, A. J. 2001. Corn silage production and management. Agronomy Facts 18. The Pennsylvania State University, University Park, PA.

50. Rundberget, T., and Wilkins, A. L. 2002. Determination of Penicillium mycotoxins in foods and feeds using liquid chromatography-mass spectrometry. J. Chromatogr. A. 964:189-197.

51. Sabater-Vilar, M., Maas, R. F. M., De Bosschere, H., Ducatelle, R., and Fink-Gremmels, J. 2004. Patulin produced by an Aspergillus clavatus isolated from feed containing malting residues associated with a lethal neurotoxicosis in cattle. Mycopathologia 158:419-426.

52. Schneweis, I., Meyer, K., Hormansdorfer, S., and Bauer, J. 2000. Mycophenolic acid in silage. Appl. Environ. Microbiol. 66:3639-3641.

53. Scott, P. M. 1995. Natural toxins. Pages 1-49 in: Official Methods of Analysis of the Association of Official Analytical Chemists (AOAC) Intl. 16th ed. P. Cuniff, ed. AOAC, Arlington, VA.
54. Scott, P. M., Kennedy, B. P. C., Harwig, J., and Blanchfield, B. J. 1977. Study of the conditions for production of roquefortine and other metabolites of Penicillium roqueforti. Appl. Environ. Microbiol. 33:249253.

55. Scudamore, K. A., and Livesey, T. 1998. Occurrence and significance of mycotoxins in forage crops and silage: A review. J. Sci. Food Agric. 77:117.

56. Smith, P. A., Nelson, T. S., Kirby, L. K., Johnson, Z. B., and Beasley, J. N. 1983. Influence of temperature, moisture, and propionic acid on mold growth and toxin production on corn. Poultry Sci. 62:419-423.

57. Still, P. E., Wei, R. D., Smalley, E. B., and Srong, F. M. 1972. A mycotoxin from Penicillium roqueforti isolated from toxic cattle feed. Fed. Proc. 31:733

58. Sumarah, M. W., Miller, J. D., and Blackwell, B. A. 2005. Isolation and metabolite production by Penicillium roqueforti, $P$. paneum and $P$. crustosum isolated in Canada. Mycopathologia 159:571-577.

59. Tapia, M. O., Stern, M. D., Koski, R. L., Bach, A., and Murphy, M. J. 2002. Effects of patulin on rumen microbial fermentation in continuous culture fermenters. Anim. Feed Sci. Tech. 97:239-246.

60. Tuller, G., Armbruster, G., Wiedenmann, S., Hanichen, T., Schanms, D., and Bauer, J. 1998. Occurrence of roquefortine in silage - toxicological relavance to sheep. J. Anim. Physiol. An. N. 80:246-249.

61. Vesely, D., Vesela, D., and Adamkova, A. 1981. Occurrence of Penicillium roqueforti producing PR toxin in maize silage. Vet. Med-Czech 26:109115.

62. Young, K. L., Villar, D., Carson, T. L., Ierman, P. M., Moore, R. A., and Botoff, M. R. 2003. Tremorgenic mycotoxin intoxication with penitrem A and roquefortine in two dogs. J. Am. Vet. Med. Assoc. 222:52-53.

63. Yu, W., Yu, F. Y., Undersander, D. J., and Chu, F. S. 1999. Immunoassays of selected mycotoxins in hay, silage, and mixed feed. Food Agric. Immun. 11:307-319.

64. Zar, J. H. 1999. Pages 177-230 in: Biostatistical Analysis. 4th ed. Prentice-Hall, Englewood Cliffs, NJ. 